\title{
Byssus secretion of Mytilus galloprovincialis: effect of site at macro- and micro-geographical scales within Ría de Vigo (NW Spain)
}

\author{
Jose M. F. Babarro ${ }^{1, *}$, Emily Carrington ${ }^{2}$ \\ ${ }^{1}$ Instituto de Investigaciones Marinas CSIC, Eduardo Cabello 6, 36208 Vigo, Spain \\ ${ }^{2}$ Friday Harbor Laboratories, Department of Biology, University of Washington, Friday Harbor, Washington 98250, USA
}

\begin{abstract}
The effect of the abiotic environment on byssus tenacity and associated features was investigated for Mytilus galloprovincialis in the Ría de Vigo (NW Spain). The effect of site was examined at macro-geographical (outer exposed Cabo Estay vs. inner sheltered San Simón Ensenada sites) and micro-geographical (intertidal vs. subtidal locations) scales. Site significantly influenced byssus tenacity, shape and byssus thread diameter, whereas location did not. Qualitative analysis of the byssus corroborated the importance of site; mussels inhabiting the rougher outer Ría secreted stronger and stiffer threads regardless of location and had a higher potential to form cross-links or metal chelation in the byssal collagen to gain structural integrity when needed. When mussels were transplanted between exposed and sheltered sites, asymmetrical changes were observed in tenacity, endogenous indices, byssus morphology and mechanical properties after 3 mo. Individuals transferred from the sheltered to the exposed site shifted all variables, suggesting that mussels have a plastic response to rougher environments by increasing byssus size and mechanical integrity. In contrast, mussels transplanted from the exposed to the sheltered site shifted tenacity, endogenous indices and thread length but not thread diameter nor mechanical properties. In summary, we report the highly dynamic nature of the mussel ability to modify byssus tenacity when subjected to abrupt environmental changes. Mussels have the potential to change byssus diameter and mechanical properties to increase strength in stressful abiotic conditions, and can re-allocate energy for vital structures such as gonadal and soft tissue growth in more benign environments.
\end{abstract}

KEY WORDS: Mytilus galloprovincialis · Tenacity · Field · Byssus secretion · Abiotic environment · Tidal exposure $\cdot$ Plasticity Resale or republication not permitted without written consent of the publisher

\section{INTRODUCTION}

In the tidal zone of estuaries, environmental factors such as temperature, salinity, aerial exposure and hydrodynamics represent key factors in the determination of population dynamics. Mussels are sessile and gregarious organisms capable of withstanding hydrodynamic challenges of the sea owing to their ability to secrete an extracellular structure named byssus, an array of collagenous threads secreted in the ventral groove of the foot (Waite 1992). Each thread is proximally attached to a common stem that connects via the root to the byssus retractor muscle (Brown 1952) and distally to the substratum through the adhesive plaque.
The byssus threads have to be replaced continuously because of they decay over time (approximately 4 to 6 wk; Carrington 2002, Moeser \& Carrington 2006). The process of thread replacement can represent up to $8-15 \%$ of the total energy expenditure of the mussel (Hawkins \& Bayne 1985). Moreover, a morphological feature like shell mass or thickness, which affects the survival of intertidal animals facing aerial exposure, wave action and predation, may represent a high metabolic cost (up to $25-50 \%$ of the total energy that can be allocated into the shell formation; Gardner \& Thomas 1987). Different environments within the same estuary (i.e. sheltered vs. exposed areas) may cause several morphological changes in corporal parameters 
of the mussels, such as shell thickness, height and width (Raubenheimer \& Cook 1990, Akester \& Martel 2000, Steffani \& Branch 2003, Beadman et al. 2003), and shift energy allocation patterns to other vital structures. Unbalanced patterns in energy allocation between shell and soft tissue growth, reproductive tissues and byssal attachment may be more common in littoral zones with limited food availability than in subtidal environments where food resources are more abundant (Lachance et al. 2008).

Many factors (biotic and abiotic) influence attachment strength of mussels, such as temperature, salinity, wave action, food availability and predators. Consequently, the influence of the latter factors may establish temporal and spatial variability in byssus secretion. Variability in attachment strength of individuals has been proposed to be based not only on the number of byssal threads secreted by the animals, but also on thread thickness (Bell \& Gosline 1997, Zardi et al. 2007, Babarro et al. 2008, Babarro \& Fernández Reiriz 2010). Moeser et al. (2006) reported that seasonal variations in attachment strength do not always reflect variability in thread number, which suggests that other factors might play a significant role, such as thread mechanical properties, decay rates and other endogenous parameters such as reproductive condition. Tensile mechanical properties of the byssus were quantified in several surveys (Smeathers \& Vincent 1979, Bell \& Gosline 1996, Carrington \& Gosline 2004, Brazee \& Carrington 2006), in which the breaking force was estimated as the maximum force supported by an individual thread and the breaking strain corresponded to the total distance a thread can extend before failure divided by the initial thread length (Moeser \& Carrington 2006). In general terms, strength of the entire byssal structure should increase with an increase of breaking force and strain; higher extensibility allows the individual thread to stretch and realign within the byssal complex in order to realign and recruit more threads facing the load (Bell \& Gosline 1996). The extensibility of the byssus in Mytilus sp. is due to the proximal section and the yield behaviour of the distal section (becoming less stiff) before thread failure, which establishes a triphasic pattern for the wholethread tensile behaviour for many Mytilus species (Bell and Gosline 1996): threads are initially stiff, then yield, and finally stiffen again before structural failure.

When plasticity patterns, in qualitative terms, are considered for the byssus structure of the mussels under stressful conditions, there is evidence for the formation of quinone-derived cross-links in mussel byssal plaques, with enhanced levels of 5,5'-dihydroxyphenyl-alanine cross-links when individuals are exposed to increasing flow regimes (McDowell et al. 1999). The whole thread structure is mainly collage- nous (Pujol et al. 1970, 1976, Sun \& Waite 2005) but the distal part has a supplementary composition of alanine and glycine that makes it similar to silk fibroin (Qin \& Waite 1998) whereas the proximal section has additional components similar to those encountered in elastin (Coyne et al. 1997, Waite et al. 2002). Both proximal and distal sections have common histidinerich residues at their terminal flanking domains with important implications for the intra- and inter-molecular stabilization of assembled collagenous proteins in the byssus (Qin \& Waite 1998). Specifically for the byssal collagens, metal chelate formation joining $\mathrm{Zn}^{2+}$, $\mathrm{Cu}^{2+}$ and $\mathrm{Fe}^{2+}$ represents a significant cross-link alternative involving histidine, dopa (3,4-dihydroxyphenyl alanine) or even cysteine residues (Lucas et al. 2002, Harrington \& Waite 2007) that gives integrity and structural strength to the byssus apparatus. Recently, we have reported how the amount of basic residues, i.e. histidine and lysine, in the byssal collagen represent a significant contribution to the byssal strength of mussels under endogenous stress such as postspawning events (Babarro \& Fernández Reiriz 2010), although results of this work referred only to the distal section of the byssal filaments.

Mytilus galloprovincialis represents a widely distributed and cultured bivalve along the coastline of Rías Gallegas (NW Spain) and individuals may tolerate occasionally abrupt fluctuations of the abiotic factors between the outer and inner sites of the Rías. Here, we examine the influence of the spatial gradient along the Ría de Vigo between the outer exposed vs. inner sheltered littoral sites as well as the vertical tidal zone gradient (intertidal vs. subtidal locations) on several phenotypic characteristics of rocky shore mussels, including endogenous parameters and byssus morphology, mechanics and composition. Reciprocal transplant experiments were designed to test the hypotheses that: (1) both horizontal (outer vs. inner Ría) and vertical (intertidal vs. subtidal) spatial gradients along the Ría de Vigo affect byssal attachment strength; and (2) differences in mussel tenacity between experimental locations reflect differences in byssus morphometry and material properties.

\section{MATERIALS AND METHODS}

Environment. Field studies were conducted at 2 littoral sites of Ría de Vigo with strong differences in environmental conditions. Both experimental sites are located near the city of Vigo and are $30 \mathrm{~km}$ apart (Fig. 1): one site at the exposed outer Ría Cabo Estay (CE) and the other at the inner sheltered zone in the Ensenada of San Simón (SS). Experiments were performed during fall 2007 and spring-summer 2008. For 


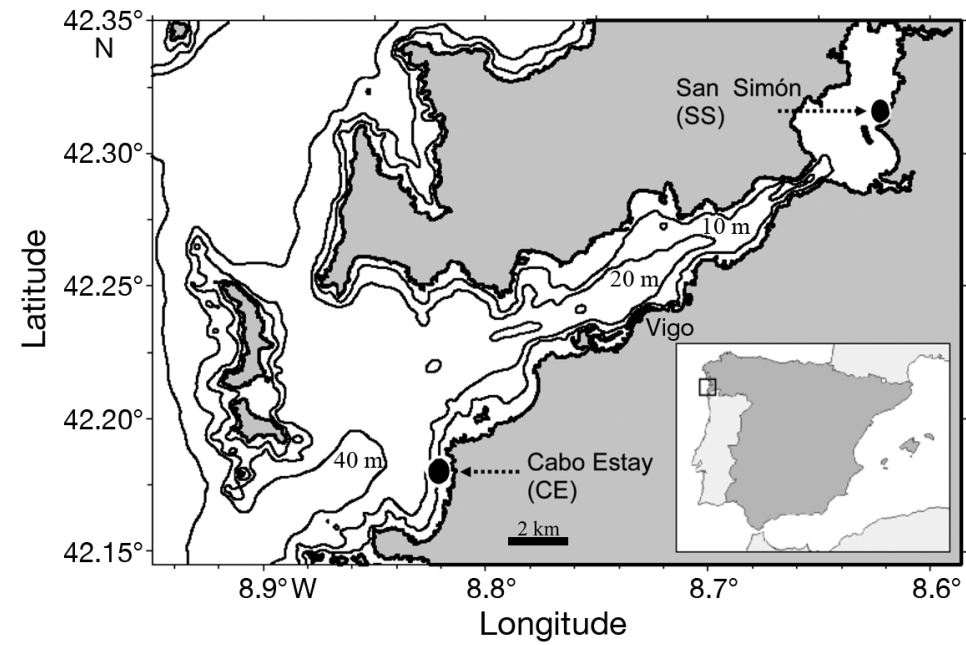

Fig. 1. Experimental sites in Ría de Vigo (NW Spain). Cabo Estay (CE) and San Simón (SS) indicate the outer exposed and inner sheltered experimental locations of the survey, respectively

the first outplant experiment (fall 2007), 2 spatial gradients were considered: one along a horizontal line from the outer exposed (CE) to the inner sheltered (SS) site and the other a vertical gradient within each site from intertidal to subtidal locations (20 to $0 \%$ air exposure, respectively). The main goal was to investigate the significance of both macro- and micro-geographical environmental levels on mussel tenacity and associated features. This experiment lasted for 3 mo from October to December 2007. A second reciprocal transplant experiment was performed between outer exposed and inner sheltered intertidal sites with the main goal of investigating the plasticity patterns in the mussel's performance under changing environments. This survey was carried out between May and July 2008. Environment in both experiments was characterised by analyzing seawater (weekly) from experimental sites for total particulate matter (TPM) and chlorophyll a (chl a) values. Temperature was measured by using Vemco data loggers. Salinity, current speed and wave height of seawater were obtained from Reports of MeteoGalicia for both experimental sites (Xunta de Galicia, Autonomic Government).

Outplant and transplant design. Subtidal individuals of Mytilus galloprovincialis ( $4.5 \mathrm{~cm}$ shell length) were collected from a raft system in the Ría of Vigo and used for the outplant experiment during fall 2007. Two sets of slates were placed at each site (Fig. 2), 1 for the intertidal and 1 for the subtidal location. Each set consisted of 4 slates per population (A-D) with 20 individuals per slate
( $n=80$ for each site). With an initial number of 80 mussels, we ensured reliable samples sizes for the different tests proposed. Mussels were allowed to establish primary attachment in the laboratory for $2 \mathrm{~d}$ before transportation to the experimental sites to avoid difficulties in establishing byssus under natural tidal conditions. Nylon net was used to cover mussel populations, allowing the seawater to flow in but preventing initial predation by macro-invertebrates when attachment was weak during the first days after transportation from the laboratory. After this initial period in the field, the net was progressively cut. Therefore, individuals were allowed to freely attach to slates and were naturally exposed to each environment.

For the reciprocal transplant experiment (spring-summer 2008), mussels from the outer exposed CE and inner sheltered SS intertidal sites were carefully collected $(4.5-4.9 \mathrm{~cm}$ shell length) and transported to the laboratory for a few days. Byssal threads were removed by snipping them with scissors to avoid pulling them by hand and disturbing the byssus structure or the foot organ. Individuals from each intertidal site were divided into 2 subgroups, native (returned to original sites; $\mathrm{SS} \rightarrow \mathrm{SS}$ and $\mathrm{CE} \rightarrow \mathrm{CE}$ ) and transplanted (moved to new site; $\mathrm{SS} \rightarrow \mathrm{CE}: \mathrm{CE} \rightarrow \mathrm{SS}$ ). A slate assemblage similar to that used in the outplant experiment was designed.

Tenacity. Attachment force of individuals from each experimental site was measured by connecting the mussel to a spring scale (Kern $\mathrm{MH}, 0.01 \mathrm{~N}$ resolution) with a thin monofilament fishing line through a $2 \mathrm{~mm}$ diameter hole drilled through the shell valves close to the posterior margin. Dislodgment force of the mussels from the substratum was then recorded. The spring scale was pulled perpendicular (normal) to the sub-

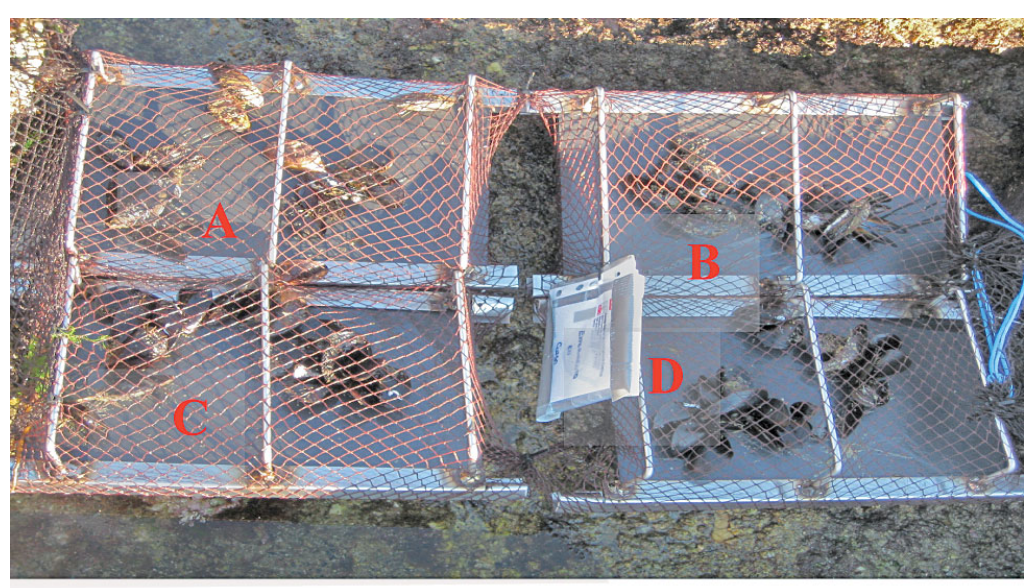

Fig. 2. Outplanting experimental mussels; 20 individuals on each of the 4 slates (A to D) in the field 
strate until dislodgement occurred (Bell \& Gosline 1997, Babarro \& Fernández Reiriz 2010). Attachment force $(F)$ was normalized by mussel size in order to obtain tenacity $\left(T, \mathrm{~N} \mathrm{~m}^{-2}\right)$ according to the formula $T=F / A_{\mathrm{P}}$, where $A_{\mathrm{P}}$ is the projected area of the individuals $\left(\mathrm{m}^{-2}\right.$; see next paragraph). Only animals directly attached to the slate surface were considered.

Shape and, gonadal and condition indices. After dislodgment, mussels were measured according to the antero-posterior (shell length), dorso-ventral (height) and lateral (width) axes to the nearest millimetre with vernier calipers. The shell area of the experimental mussels was measured by image analysis (IA) of an ellipse with shell height and width as major and minor axes, respectively. IA measurements were performed using the software QWin (Leica Imaging Systems) on a PC (AMD Athlon XP 3000+) connected to a video camera (Leica IC A) on a stereo microscope (Leica MZ6). Camera and light settings were established at the beginning of the analysis and kept constant throughout the analysis. Shell thickness was determined as the shell mass:surface area ratio (Beadman et al. 2003). The mass of the shell was determined as described below (see condition index) and the surface area $\left(A_{\mathrm{S}}\right.$ $\mathrm{cm}^{2}$ ) of the shell was estimated following the formula $A_{\mathrm{S}}=1\left(h^{2}+w^{2}\right)^{0.5} 0.5 \pi$, where $l$ is length $(\mathrm{cm}), w$ is width $(\mathrm{cm})$ and $h$ is height $(\mathrm{cm})$.

Condition index was obtained according to the formula: $C I=\left(D W_{\text {tissue }} / D W_{\text {shell }}\right) \times 100$, where $D W_{\text {tissue }}$ is the dry weight of soft tissues and $D W_{\text {shell }}$ is the dry weight of the shell (Freeman 1974). Gonadal index was obtained as the proportion of mussel biomass composed of mantle tissue (site of gametogenesis in Mytilus). Wet mantle was dissected from the wet body and, together with the rest of the organs, was freezedried for $48 \mathrm{~h}$. Samples of the mantle and the rest of tissues were weighed to the nearest $0.001 \mathrm{~g}$ and gonadal index was calculated as the dry weight of the mantle divided by the whole soft body (sum of the dry weight of the mantle and remaining tissues) (Carrington 2002, Babarro \& Fernández Reiriz 2010).

Byssus size, mechanical properties and amino acid composition. Thickness and length of the threads secreted by the mussels in situ were measured by IA performed on 30-40 threads for each experimental population. Byssal threads of Mytilus sp. are ovate in cross-section (Smeathers \& Vincent 1979, Brazee \& Carrington 2006), which creates elliptical profiles with a major and minor axis. Here, IA performed for thread's diameter measurements refer to photographs of the thread cross sections (by microtome) in a stereo microscope. In order to collect the entire byssus, mussels (not manipulated) adjacent to those used for dislodgement measures were used. Proximal and distal portions of the thread were subdivided into sections along the thread in order to get an integrated measure of both portions.

The tensile properties of byssal threads from the different experimental mussel populations were tested according to Bell \& Gosline (1996) using an Instron5565 tensometer. Maximum load (N), strain at maximum load, initial modulus (MPa), yield force $(\mathrm{N})$ and scaled force to break (N) were measured for whole threads, and material strength values were measured separately for proximal and distal thread regions. All mechanical tests were conducted in seawater at $15 \pm$ $1^{\circ} \mathrm{C}$ at an extension rate of $10 \mathrm{~mm} \mathrm{~min}^{-1}$.

The percentage of collagen content in the byssal threads can be estimated by quantifying the amount of hydroxyproline. Collagen quantity and quality (amino acid composition) was measured for both proximal and distal sections of the byssal threads of the experimental mussels. Hydrolysis of the byssal collagen was performed following Lucas et al. (2002). Briefly, proximal and distal segments of the threads were hydrolysed in $6 \mathrm{~mol}^{-1} \mathrm{HCl}$ with $0.01 \mathrm{ml}$ redistilled phenol. Three replicates of 5 mussels each were used for HPLC analysis of each mussel population, pooling $3-5$ proximal and distal segments from each mussel. Threads were hydrolysed in vacuo for $24 \mathrm{~h}$ at $110^{\circ} \mathrm{C}$ and samples were then flash-evaporated at $60^{\circ} \mathrm{C}$. A volume of perchloric acid was added to the dry hydrolysed thread material and amino acids were quantified following Babarro \& Fernández Reiriz (2010). Determination of amino acids was performed by reverse-phase HPLC of the dabsyl derivatives. Amino acid standards and dabsyl chloride were purchased from Sigma. The amino acid separation method consisted of a slight modification of that reported by Krause et al. (1995), changing the dilution buffer by a mixture of both mobile phases A and B (see end of this paragraph) in the same proportion as that used at the starting point of the gradient profile. The chromatograph was a Waters Alliance HPLC System with a 2690 separations module and a Waters 996 photodiode array detector (440-480 nm). The stationary phase was a $\mathrm{C}_{18}$ column (Waters Symmetry, $150 \times 4.6 \mathrm{~mm}, 3.5 \mu \mathrm{m}$ particle size, $10 \mathrm{~nm}$ pore size) thermostated at $50^{\circ} \mathrm{C}$ by an Alliance System column oven. Twenty microliters of the derivatized samples were injected. Dabsylated amino acids were eluted at a flow rate of $1 \mathrm{ml} \mathrm{min}^{-1}$ using a gradient made with phases A $(9 \mathrm{mM}$ sodium dihydrogenphosphate, $4 \%$ dimethylformamide and $0.1-0.2 \%$ triethylamine titrated to $\mathrm{pH} 6.55$ with phosphoric acid) and B (80\% aqueous acetonitrile), with a gradient profile that corresponds to that used by Pinho et al. (2001). For quantification, nor-leucine was used as internal standard.

Statistical analysis. Two-way ANOVA was used to estimate the effects of both site (outer exposed CE and 
inner sheltered SS) and location (intertidal and subtidal) on the endogenous parameters (shape, byssus morphology and soft tissues state), tenacity, byssal mechanical properties and amino acid composition (all dependent variables were log-transformed) of mussels in the outplant experiment. Two-way ANOVA was also used to estimate the effects of both site and origin of native and transplanted mussels (spring-summer 2008) on the same log-transformed variables described before. Homogeneous groups were established a posteriori by using Tukey's test. When variances were not homogeneous (Levene's test), non-parametric Kolmogorov-Smirnov tests and Mann-Whitney $U$-tests were used. A $t$-test was used to establish differences in shape and morphological values of mussels at the beginning ( $\mathrm{CE}, t=0 ; \mathrm{SS}, t=0$ ) and end of the experiment as well as those of transplanted individuals with regard to their original sites. A $t$-test was also used for specific comparisons between amino acid residues of the 2 distinct regions of the byssus, i.e. proximal and distal. All analyses were performed using STATISTICA 6.0 software.

\section{RESULTS}

\section{Outplant experiment: effect of horizontal and vertical spatial gradients}

\section{Environment}

Abiotic conditions for the outer exposed CE and inner sheltered SS experimental sites at Ría de Vigo are presented in Fig. 3. Daily maximum temperature values of the air-seawater interface fluctuated widely at both intertidal $\left(11.5-29.4^{\circ} \mathrm{C}\right)$ and subtidal (11.5$21.2^{\circ} \mathrm{C}$ ) locations at both inner (Fig. 3A) and outer (Fig. 3C) sites. Mean air-seawater interface temperature values for both intertidal and subtidal locations were $13.4-14.1^{\circ} \mathrm{C}$ and $12.3-12.5^{\circ} \mathrm{C}$ for the outer exposed CE and inner sheltered SS sites, respectively. Daily minimum and maximum salinity values varied between 34.5-35.9 psu and 22.3-31.4 psu for both the outer exposed CE (mean $=35.5 \mathrm{psu}$ ) and the inner sheltered SS (mean = 25.9 psu) sites, respectively (Fig. 3B). Mean values of current speed and wave height were approximately 2- and 15-fold higher at the exposed outer site CE $\left(0.08 \pm 0.04 \mathrm{~m} \mathrm{~s}^{-1}\right.$ and $1.20 \pm 0.61 \mathrm{~m}$, respectively) compared with the inner sheltered SS $\left(0.04 \pm 0.03 \mathrm{~m} \mathrm{~s}^{-1}\right.$ and $0.08 \pm 0.05 \mathrm{~m}$, respectively) (Fig. 3D,E). Chl a values were similar between both sites $\left(1.6-1.9 \mu \mathrm{g} \mathrm{l}^{-1}\right)$, with the exception of the highest value reported at the outer exposed CE in October 2007 (5.3 $\mathrm{gg} \mathrm{l}^{-1}$ ) (Fig. 3F). TPM showed constant values for the outer exposed CE site (approximately $0.8 \mathrm{mg}$ $\mathrm{l}^{-1}$ ) and much higher variability for the inner sheltered
SS site, between minimum values of $0.4 \mathrm{mg} \mathrm{l}^{-1}$ and maximum values of $5.8 \mathrm{mg} \mathrm{l}^{-1}$ (Fig. 3F).

\section{Body size parameters}

Mussels living at the outer exposed CE site had significantly higher shell width and lower shell height than those from the inner sheltered SS site $(\mathrm{p}<0.001$; Table 1). No significant differences were encountered for vertical zonation (location). Because of the inverse pattern between differences in height and width values of mussels, shell area differences of the individuals were balanced and not significantly different between sites (approximately $4.9 \mathrm{~cm}^{2}$ mean values for both populations) but significantly higher values were reported for subtidal $\left(5.3 \mathrm{~cm}^{2}\right)$ vs. intertidal $\left(4.6 \mathrm{~cm}^{2}\right)$ locations ( $p<0.05$; Table 1). Shell thickness was significantly different by site but not by vertical distribution (location) of the mussels (Table 1), values being 14-24\% higher in the outer exposed CE population $(p<0.001)$ compared with the inner sheltered SS population. By contrast, gonadal (GI) and condition index (CI) values were significantly higher in the inner sheltered SS population compared with the outer exposed CE population, also regardless of vertical zonation (location), values ranging from $25 \%$ (GI) and $18 \%$ (CI) in the inner sheltered SS population to $13-18 \%$ (GI and CI) in the outer exposed CE population (Table 1).

\section{Tenacity}

Variability of mussel tenacity according to site and vertical zonation (location) is presented in Table 2. Mussel tenacity varied significantly with site (ANOVA, $\mathrm{p}<0.01$ ) but not with location in the littoral coastline. Tenacity was significantly higher in the outer exposed CE mussels regardless of intertidal or subtidal location (approximately $4.5 \times 10^{-4} \mathrm{~N} \mathrm{~m}^{-2}$ ) compared with the inner sheltered SS mussels $\left(2.9-3.6 \times 10^{-4} \mathrm{~N} \mathrm{~m}^{-2}\right.$ for both littoral locations).

\section{Byssus size, mechanical properties and amino acid composition}

Thickness and length values of the byssus secreted according to site and vertical zonation (location) are presented in Table 2. Only distal sections of the byssus varied significantly by site (ANOVA, $\mathrm{p}<0.01$ ), but these sections did not vary by vertical zonation (location). Distal thickness was significantly higher in the outer exposed CE mussels (97-106 $\mu \mathrm{m}$ for both intertidal and subtidal populations) compared with the inner shel- 

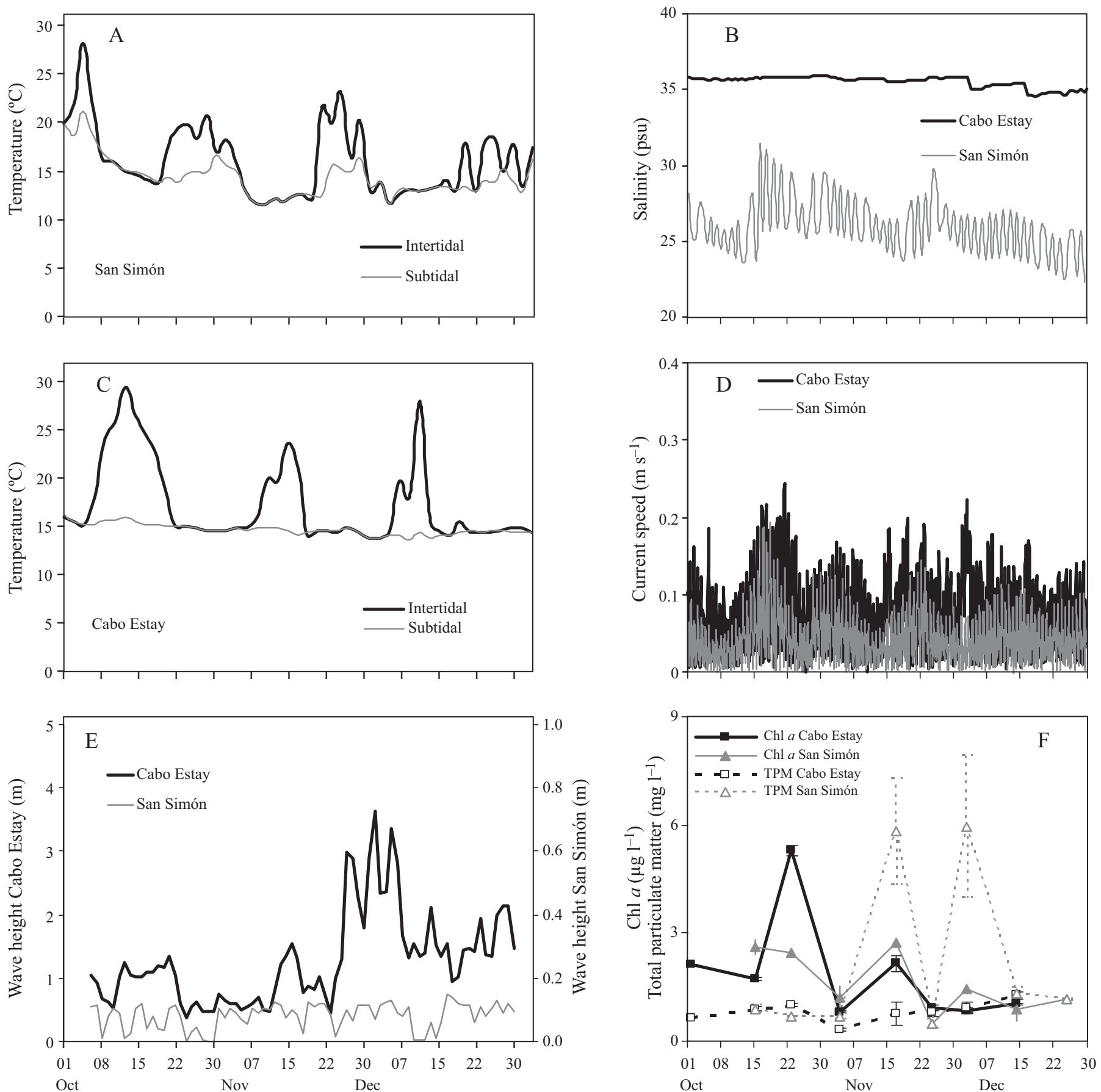

Fig. 3. Outplant experiment. $(A, C)$ Daily maximum of temperature, $(B)$ daily maximum and minimum of salinity, (D) current speed, (E) mean daily wave height and (F) chlorophyll a ( $\mathrm{chl} \mathrm{a}$ ) and total particulate matter (TPM) in the seawater reported for the sampling period at both outer exposed (Cabo Estay) and inner sheltered (San Simón) sites

tered SS mussels (90-95 $\mu \mathrm{m})$. No significant differences were observed for the proximal sections of the byssus secreted by mussels with respect to site and location (159-170 $\mu \mathrm{m})$. Similarly, no significant effect was reported for site and location on the length of the byssus secreted by experimental mussels; values ranged between 16 and $20 \mathrm{~mm}$ for all experimental conditions.
A number of mechanical properties of the threads secreted by the experimental mussels in the field are presented in Table 3. Site had a significant effect on maximum load, modulus, yield, proximal strength and scaled force values of the byssal threads, although location did not produce any effect. Strain and distal strength did not change significantly with either site or 
Table 1. Mytilus galloprovincialis. Characteristics of the individuals in the outplant experiment. Means \pm SD $(n=9)$

\begin{tabular}{|c|c|c|c|c|c|c|c|c|c|c|}
\hline \multirow[t]{2}{*}{ Population } & \multirow[t]{2}{*}{$\begin{array}{l}\text { Width } \\
(\mathrm{cm})\end{array}$} & \multirow[t]{2}{*}{$\underset{(\mathrm{cm})}{\text { Height }}$} & \multirow[t]{2}{*}{$\begin{array}{l}\text { Shell } \\
\text { Area } \\
(\mathrm{cm})\end{array}$} & \multirow[t]{2}{*}{$\begin{array}{l}\text { Thickness } \\
\left(\mathrm{mg} \mathrm{cm}^{-2}\right)\end{array}$} & \multirow[t]{2}{*}{$\begin{array}{l}\text { Gonadal } \\
\text { index } \\
(\%)\end{array}$} & \multirow[t]{2}{*}{$\begin{array}{l}\text { Condition } \\
\text { index } \\
(\%)\end{array}$} & \multicolumn{4}{|c|}{$\begin{array}{cc}\text { Hydroxyproline }+ & \text { Histidine }+ \\
\text { hydroxylysine } & \text { lysine } \\
(\% \text { hydrolysed byssal threads; } \mathrm{n}=3 \text { ) }\end{array}$} \\
\hline & & & & & & & Proximal & Distal & Proximal & Distal \\
\hline \multicolumn{11}{|c|}{ Exposed (Cabo Estay) } \\
\hline Subtidal & $2.31 \pm 0.17$ & $2.20 \pm 0.12$ & $5.43 \pm 0.38$ & $154.66 \pm 9.63$ & $18.95 \pm 3.12$ & $13.49 \pm 1.37$ & $8.31 \pm 0.81$ & $10.20 \pm 1.01$ & $4.14 \pm 0.71$ & $2.71 \pm 0.36$ \\
\hline Intertidal & $2.11 \pm 0.07$ & $2.26 \pm 0.15$ & $4.51 \pm 0.35$ & $145.78 \pm 11.74$ & $13.69 \pm 3.37$ & $12.55 \pm 0.95$ & $8.01 \pm 0.56$ & $10.81 \pm 0.82$ & $5.01 \pm 0.45$ & $3.15 \pm 0.32$ \\
\hline \multicolumn{11}{|c|}{ Sheltered (San Simón) } \\
\hline Subtidal & $1.76 \pm 0.05$ & $2.82 \pm 0.15$ & $5.01 \pm 0.29$ & $118.93 \pm 22.32$ & $25.17 \pm 3.22$ & $17.57 \pm 1.68$ & $8.12 \pm 0.81$ & $11.10 \pm 0.88$ & $2.61 \pm 0.21$ & $1.68 \pm 0.13$ \\
\hline Intertidal & $1.77 \pm 0.07$ & $2.74 \pm 0.08$ & $4.83 \pm 0.25$ & $125.76 \pm 6.69$ & $25.81 \pm 3.98$ & $18.45 \pm 1.49$ & $9.10 \pm 0.36$ & $12.01 \pm 1.10$ & $3.01 \pm 0.12$ & $2.02 \pm 0.20$ \\
\hline
\end{tabular}

Table 2. Mytilus galloprovincialis. Mussel tenacity and morphological (thickness and length) values of the byssus secreted by the individuals in the outplant experiment. Values are means \pm SD ( $=7$ for tenacity and thread length; $\mathrm{n}=30-40$ for byssus thickness). NS: not significant

\begin{tabular}{|c|c|c|c|c|c|c|c|c|c|c|c|c|c|c|c|c|}
\hline Population & \multicolumn{4}{|c|}{ Tenacity $\left(\times 10^{-4} ; \mathrm{N} \mathrm{m}^{-2}\right)$} & \multicolumn{4}{|c|}{ Proximal byssus thickness $(\mu \mathrm{m})$} & \multicolumn{4}{|c|}{ Distal byssus thickness ( $\mu \mathrm{m})$} & \multicolumn{4}{|c|}{ Thread length (mm) } \\
\hline \multicolumn{17}{|c|}{ Exposed (Cabo Estay) } \\
\hline Subtidal & \multicolumn{4}{|c|}{$\begin{array}{l}4.4 \pm 1.2 \\
4.5 \pm 1.5\end{array}$} & \multicolumn{4}{|c|}{$\begin{array}{l}165.9 \pm 12.9 \\
158.8 \pm 16.1\end{array}$} & \multicolumn{4}{|c|}{$\begin{array}{c}97.5 \pm 8.3 \\
106.0 \pm 6.9\end{array}$} & \multicolumn{4}{|c|}{$17.7 \pm 2.2$} \\
\hline \multicolumn{17}{|c|}{ Sheltered (San Simón) } \\
\hline Subtidal & \multicolumn{4}{|c|}{$2.9 \pm 0.6$} & \multicolumn{4}{|c|}{$158.7 \pm 21.4$} & \multicolumn{4}{|c|}{$89.7 \pm 6.3$} & \multicolumn{4}{|c|}{$19.0 \pm 4.6$} \\
\hline Intertidal & \multicolumn{4}{|c|}{$3.6 \pm 0.7$} & \multicolumn{4}{|c|}{$170.1 \pm 18.9$} & \multicolumn{4}{|c|}{$95.4 \pm 8.4$} & \multicolumn{4}{|c|}{$20.3 \pm 5.6$} \\
\hline 2-way ANOVA & df & MS & & $\mathrm{p}$ & df & MS & $F$ & $\mathrm{p}$ & df & MS & $F$ & $\mathrm{p}$ & df & MS & F & $\mathrm{p}$ \\
\hline \multicolumn{17}{|l|}{ Factor } \\
\hline Site & 1 & 0.609 & 10.360 & $<0.01$ & 1 & 0.0007 & 0.2 & NS & 1 & 0.079 & 10.28 & $<0.01$ & 1 & 0.145 & $3.10 \mathrm{I}$ & NS \\
\hline Location & 1 & 0.074 & 1.257 & NS & 1 & 0.015 & 4.0 & NS & 1 & 0.029 & 3.83 & NS & 1 & 0.007 & $0.14 \mathrm{I}$ & NS \\
\hline Site $\times$ Location & 1 & 0.09 & 1.566 & NS & 1 & 0.011 & 3.1 & NS & 1 & 0.002 & 0.26 & NS & 1 & 0.057 & $1.216 \mathrm{I}$ & NS \\
\hline Error & 24 & 0.05 & & & 119 & 0.0036 & & & 151 & 0.008 & & & 24 & 0.047 & & \\
\hline
\end{tabular}

location; values ranged between 0.615 and 0.801 and 54 and $87 \mathrm{MPa}$ for all experimental populations, respectively. Thread maximum load, yield and modulus values were significantly higher for the outer exposed CE mussels compared with the inner sheltered SS mussels, regardless of location. Scaled force values of the threads were also significantly higher for the outer exposed CE mussels compared with the inner sheltered SS mussels, with no effect of location. Threads secreted by outer exposed CE mussels were, therefore, significantly stronger and stiffer owing to differences in both proximal (strength) and distal (yield) sections.

Specific amino acid compositional analyses of the acid-hydrolysed distal and proximal regions of the threads secreted by the experimental mussels are shown in Table 1. Byssal collagen quantity, according to amino acid hydroxyproline (and hydroxylysine) content, was not significantly affected by site or location (ANOVA, data not shown) and this result was reported regardless of byssus section proximal or distal (see mean values in Table 1). Nevertheless, mean values of both hydroxyproline and hydroxylysine were clearly higher in the distal section (10-12\%) than in proximal segments of the byssus $(8.0-9.1 \%$; $<<0.05)$. A significant effect of site $(p<0.01)$ was observed on the histidine plus lysine residues at both proximal and distal regions of the byssus (Table 1; ANOVA results not shown). By contrast, no effect was detected for the vertical zonation (location). The sum of histidine and lysine residues was higher in the threads secreted by the outer exposed CE mussels regardless of proximal $($ mean $=4.5 \%)$ or distal $($ mean $=3 \%)$ sections of the byssus compared with the inner sheltered SS mussels (mean $=2.8 \%$ and $1.8 \%$ for proximal and distal sections, respectively).

\section{Transplant experiment: effect of origin and site}

\section{Environment}

Air-seawater interface temperature values were $17.5 \pm 1.0^{\circ} \mathrm{C}$ and $17.9 \pm 1.9^{\circ} \mathrm{C}$ for the outer exposed $\mathrm{CE}$ and inner sheltered SS sites, respectively, with minima of $14.3^{\circ} \mathrm{C}$ (sheltered SS) and $16.1^{\circ} \mathrm{C}$ (exposed CE) and maxima of $21.9^{\circ} \mathrm{C}$ (sheltered SS) and $19.2^{\circ} \mathrm{C}$ (exposed $\mathrm{CE}$ ) (Fig. 4A). Salinity were $35.6 \pm 0.2$ and $34.2 \pm$ 
Table 3. Mytilus galloprovincialis. Mechanical properties of in situ-produced byssal threads during the outplant experiment. Means \pm SD $(n=7)$. NS: not significant

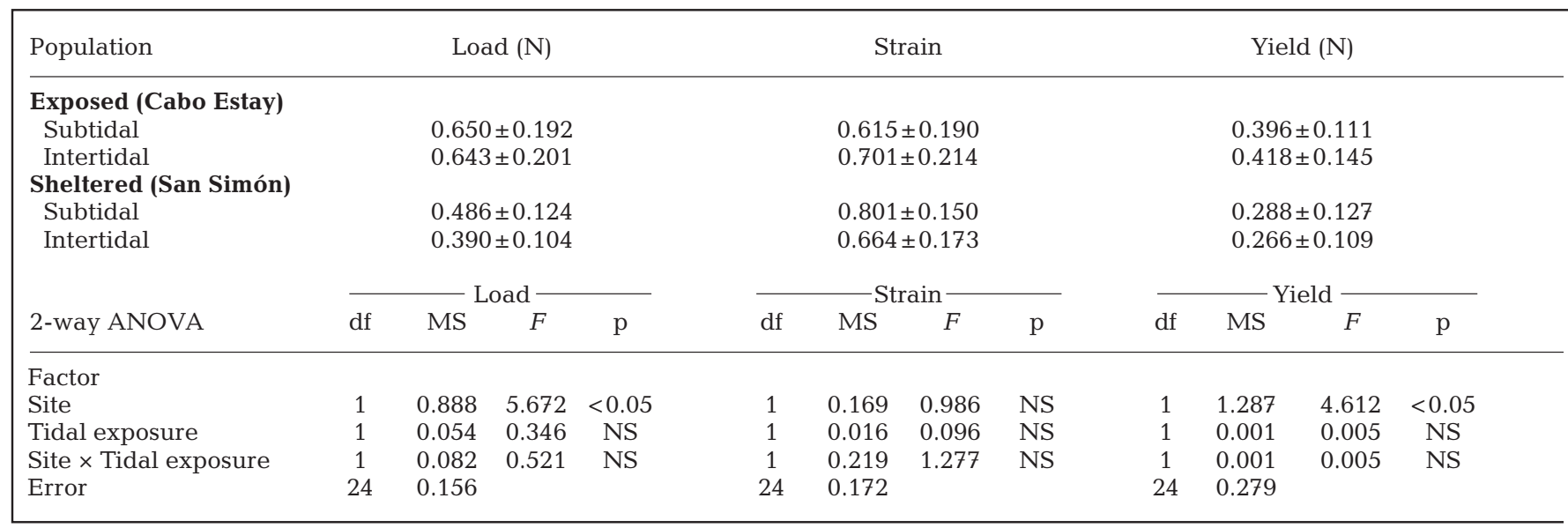

0.4 (mean $\pm \mathrm{SD}$ ) psu for both outer exposed CE and inner sheltered SS sites, respectively (Fig. 4B), with no significant fluctuations for both intertidal sites. Current flow and wave height (all mean \pm SD) were approximately 2- and 11-fold higher at the outer exposed CE site $\left(0.12 \pm 0.06 \mathrm{~m} \mathrm{~s}^{-1}\right.$ and $1.2 \pm 0.4 \mathrm{~m}$, respectively) compared with the inner sheltered SS site $(0.06 \pm 0.03$ $\mathrm{m} \mathrm{s}^{-1}$ and $0.11 \pm 0.03 \mathrm{~m}$, respectively) (Fig. $4 \mathrm{C}, \mathrm{D}$ ). Chl a values were clearly higher at the inner sheltered SS site (mean $\pm \mathrm{SD}=3.1 \pm 1.9 \mu \mathrm{g} \mathrm{l}^{-1}$ ) compared with the outer exposed CE site (mean $\pm \mathrm{SD}=0.68 \pm 0.40 \mu \mathrm{g} \mathrm{l}^{-1}$ ) (Fig. 4E) whereas TPM was also higher at the inner sheltered SS site (mean $\pm \mathrm{SD}=3.52 \mathrm{mg} \mathrm{l}^{-1}$ ), as a consequence of peak values at the beginning of the sampling period, compared with the outer exposed CE site $\left(\right.$ mean $\pm \mathrm{SD}=0.46 \mathrm{mg} \mathrm{l}^{-1}$ ) (Fig. 4F).

\section{Body size parameters}

Body size parameters of native $(\mathrm{CE} \rightarrow \mathrm{CE}$ and $\mathrm{SS} \rightarrow \mathrm{SS})$ and transplanted mussels $(\mathrm{CE} \rightarrow \mathrm{SS}$ and $\mathrm{SS} \rightarrow \mathrm{CE}$ ) from both outer exposed $\mathrm{CE}$ and inner sheltered SS sites are presented in Table 4. Growth was practically zero or residual in native $(\mathrm{CE} \rightarrow \mathrm{CE}$; $4.49 \mathrm{~cm})$ and transplanted $(\mathrm{SS} \rightarrow \mathrm{CE} ; 4.51-4.57 \mathrm{~cm})$ mussels at the outer exposed CE site compared with the initial values (experimental time $=0$ ) for both $\mathrm{CE}$ and SS mussels. Similarly, shell height remained unchanged between native $\mathrm{CE} \rightarrow \mathrm{CE}(2.26-2.30 \mathrm{~cm})$ and transplanted $\mathrm{SS} \rightarrow \mathrm{CE}(2.71-2.74 \mathrm{~cm})$ mussels during the sampling period. Shell width, however, showed a significant increase for the inner sheltered SS $(1.74 \mathrm{~cm}, \mathrm{SS} \mathrm{t}=0)$ mussels transplanted to the outer exposed site ( $\mathrm{SS} \rightarrow \mathrm{CE}, 1.83 \mathrm{~cm}$; $\mathrm{p}<0.001)$ whereas no significant change was observed for the outer exposed $\mathrm{CE} \rightarrow \mathrm{CE}$ native mussels $(1.88-1.90 \mathrm{~cm})$. As such, shell area also increased significantly $(p<0.01)$ for the for- mer population ( $\mathrm{SS} \rightarrow \mathrm{CE}$ mussels, from 4.71 at the beginning of the experiment $[t=0]$ to $5.03 \mathrm{~cm}^{2}$ after 3 mo of transplant) compared with $\mathrm{CE} \rightarrow \mathrm{CE}$ native mussels ( $p>0.05)$.

When animals are located in the inner sheltered SS site, growth was significant for several morphological values (Table 4). Shell length values of both native $(4.51-4.89 \mathrm{~cm})$ and transplanted $(4.49-4.92 \mathrm{~cm})$ mussels increased at similar rate $(\mathrm{p}<0.001$; Table 4$)$. Shell width was also reported to increase at similar rate between $\mathrm{SS} \rightarrow \mathrm{SS}$ native $(1.74-1.93 \mathrm{~cm})$ and $\mathrm{CE} \rightarrow \mathrm{SS}$ $(1.88-2.06 \mathrm{~cm})$ transplanted mussels (Table 4). However, a much higher increment was reported in shell height of the outer exposed mussels transplanted to the inner sheltered site $\left(2.26-2.46 \mathrm{~cm}\right.$ for $\mathrm{CE} \rightarrow \mathrm{SS}_{\text {; }} \mathrm{p}<$ 0.001 ) as compared to unchanged values of $\mathrm{SS} \rightarrow \mathrm{SS}$ native (2.71-2.80 cm; NS) (Table 4). Shell area values presented, therefore, a significant increase in $\mathrm{SS} \rightarrow \mathrm{SS}$ native $\left(4.71-5.41 \mathrm{~cm}^{2} ; \mathrm{p}<0.001\right)$ but also for the transplanted $\mathrm{CE} \rightarrow \mathrm{SS}$ mussels $\left(4.25-5.05 \mathrm{~cm}^{2} ; \mathrm{p}<0.001\right)$ (Table 4).

Shell thickness was significantly higher in the outer exposed $\mathrm{CE} \rightarrow \mathrm{CE}$ native mussels $\left(296 \mathrm{mg} \mathrm{cm}^{-2}\right.$ ) compared with the inner sheltered $\mathrm{SS} \rightarrow \mathrm{SS}$ native mussels $\left(222 \mathrm{mg} \mathrm{cm}^{-2}\right)$ ( $\mathrm{p}<0.001$; Fig. 5A,B). Transplanted animals modified shell thickness, increasing (248 mg $\left.\mathrm{cm}^{-2} ; \mathrm{SS} \rightarrow \mathrm{CE}\right)$ and decreasing $\left(275 \mathrm{mg} \mathrm{cm}^{-2} ; \mathrm{CE} \rightarrow \mathrm{SS}\right)$ values compared with their original sites, but values did not reach those of the native non-transplanted populations in any circumstances (Fig. 5A,B). GI and CI values showed no differences between native and transplanted individuals. Native mussels from the outer exposed $\mathrm{CE}$ site $(\mathrm{CE} \rightarrow \mathrm{CE})$ showed lower GI $(13 \%)$ and CI $(6 \%)$ values $(p<0.001)$ compared with native mussels from the inner sheltered $\mathrm{SS}$ site $(\mathrm{SS} \rightarrow \mathrm{SS}$ ) (25 and $11 \%$ for GI and CI, respectively; Fig. $5 \mathrm{C}, \mathrm{D})$. After transplantation, in both directions, mussels reached values similar to those that characterised 
Table 3 (continued)

\begin{tabular}{|c|c|c|c|c|c|c|c|c|c|c|c|c|c|c|c|}
\hline \multicolumn{4}{|c|}{ Modulus (MPa) } & \multicolumn{4}{|c|}{ Proximal strength (MPa) } & \multicolumn{4}{|c|}{ Distal strength (MPa) } & \multicolumn{4}{|c|}{ Scaled force (N) } \\
\hline \multicolumn{4}{|c|}{$\begin{array}{l}140.07 \pm 28.34 \\
106.01 \pm 34.29\end{array}$} & \multicolumn{4}{|c|}{$\begin{array}{c}30.03 \pm 13.26 \\
35.67 \pm 7.82\end{array}$} & \multicolumn{4}{|c|}{$87.04 \pm 25.30$} & \multicolumn{4}{|c|}{$0.618 \pm 0.241$} \\
\hline \multirow{2}{*}{\multicolumn{4}{|c|}{$\begin{array}{l}86.39 \pm 18.34 \\
87.34 \pm 19.83\end{array}$}} & \multirow{2}{*}{\multicolumn{4}{|c|}{$\begin{array}{l}24.54 \pm 8.37 \\
17.14 \pm 4.48\end{array}$}} & \multirow{2}{*}{\multicolumn{4}{|c|}{$\begin{array}{l}74.80 \pm 24.74 \\
54.52 \pm 14.25\end{array}$}} & \multirow{2}{*}{\multicolumn{4}{|c|}{$\begin{array}{l}0.412 \pm 0.107 \\
0.327 \pm 0.091\end{array}$}} \\
\hline & & & & & & & & & & & & & & & \\
\hline 1 & 0.823 & 10.553 & $<0.01$ & 1 & 1.013 & 6.475 & $<0.05$ & 1 & 0.197 & 1.258 & NS & 1 & 1.379 & 17.442 & $<0.01$ \\
\hline 1 & 0.187 & 2.404 & NS & 1 & 0.089 & 0.57 & NS & 1 & 0.380 & 2.428 & NS & 1 & 0.280 & 3.542 & NS \\
\hline 1 & 0.148 & 1.900 & NS & 1 & 0.344 & 2.200 & NS & 1 & 0.051 & 0.328 & NS & 1 & 0.016 & 0.201 & NS \\
\hline 24 & 0.078 & & & 24 & 0.156 & & & 24 & 0.156 & & & 24 & 0.079 & & \\
\hline
\end{tabular}
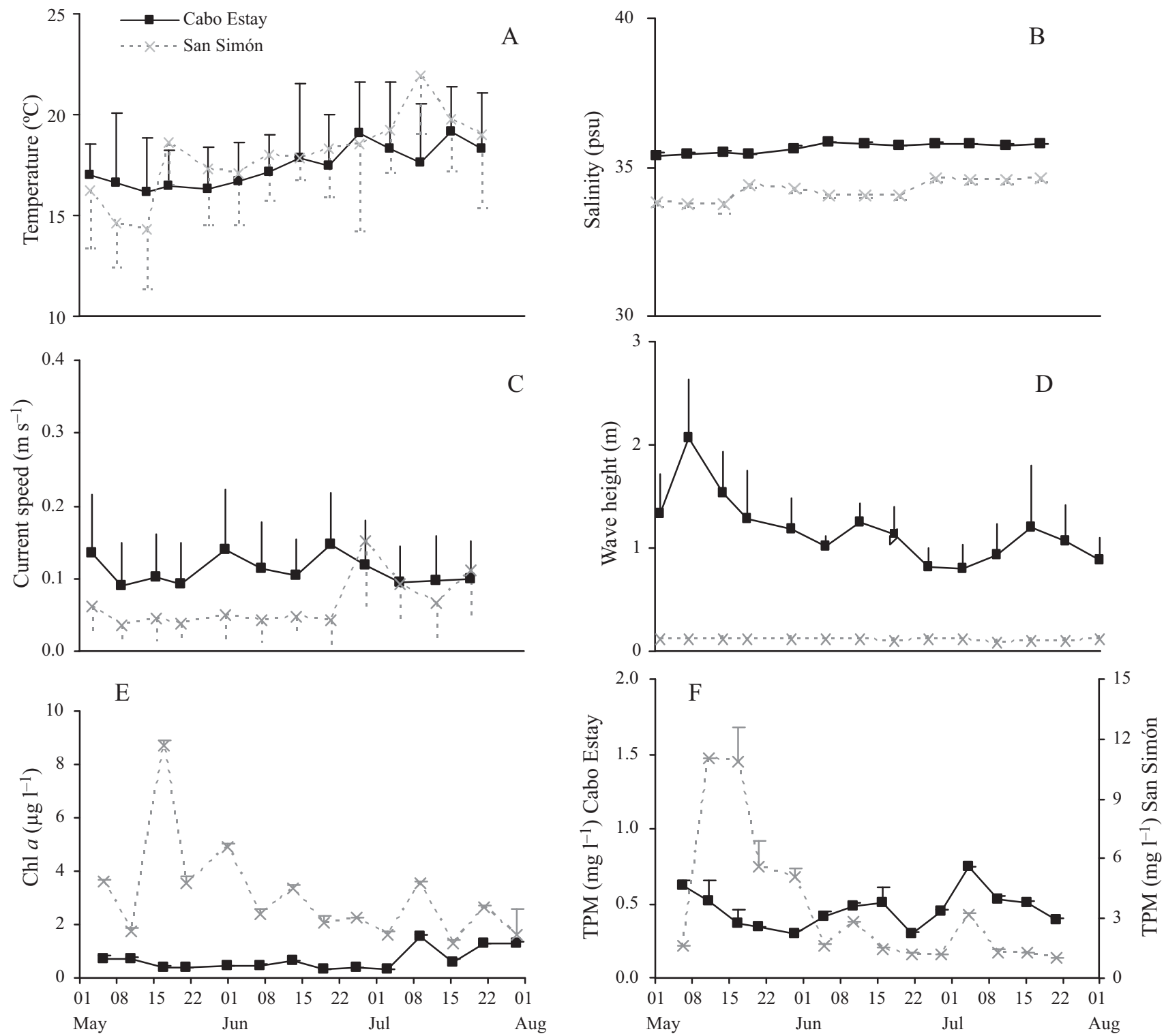

Fig. 4. Transplant experiment. (A) Weekly mean temperature, (B) salinity, (C) current speed, (D) wave height, (E) chlorophyll a and (F) total particulate matter (TPM) values of the seawater reported for the sampling period at both outer exposed Cabo Estay and inner sheltered San Simón intertidal sites 
Table 4. Mytilus galloprovincialis. Transplant experiment $(\mathrm{t}=0$ : values at the beginning at each site). Length, height, width and area of the shells of experimental mussels after transplantation between exposed and sheltered intertidal sites. Means \pm SD $(n=9)$. N-par.: non-parametric; NS: not significant ( $p>0.05$ )

\begin{tabular}{|c|c|c|c|c|}
\hline Population & Length $(\mathrm{cm})$ & Height $(\mathrm{cm})$ & Width (cm) & Area $\left(\mathrm{cm}^{2}\right)$ \\
\hline $\mathrm{CE} t=0$ & $4.49 \pm 0.19$ & $2.26 \pm 0.19$ & $1.88 \pm 0.13$ & $4.25 \pm 0.38$ \\
\hline $\mathrm{CE} \rightarrow \mathrm{CE}$ & $4.49 \pm 0.14$ & $2.30 \pm 0.15$ & $1.90 \pm 0.12$ & $4.38 \pm 0.43$ \\
\hline $\mathrm{CE} \rightarrow \mathrm{SS}$ & $4.92 \pm 0.25$ & $2.46 \pm 0.17$ & $2.06 \pm 0.14$ & $5.05 \pm 0.41$ \\
\hline $\mathrm{SS} \mathrm{t}=0$ & $4.51 \pm 0.07$ & $2.71 \pm 0.15$ & $1.74 \pm 0.10$ & $4.71 \pm 0.33$ \\
\hline $\mathrm{SS} \rightarrow \mathrm{SS}$ & $4.89 \pm 0.25$ & $2.80 \pm 0.16$ & $1.93 \pm 0.12$ & $5.41 \pm 0.45$ \\
\hline $\mathrm{SS} \rightarrow \mathrm{CE}$ & $4.57 \pm 0.12$ & $2.74 \pm 0.16$ & $1.83 \pm 0.09$ & $5.03 \pm 0.39$ \\
\hline \multicolumn{5}{|l|}{ Statistics } \\
\hline $\mathrm{CE} \mathrm{t}=0$ vs. $\mathrm{CE} \rightarrow \mathrm{CE}$ & NS & NS & NS & NS \\
\hline $\mathrm{CE} \mathrm{t}=0$ vs. $\mathrm{CE} \rightarrow \mathrm{SS}$ & $\mathrm{p}<0.001(t$-test $)$ & $\mathrm{p}<0.001$ (t-test) & $\mathrm{p}<0.001(t$-test $)$ & $\mathrm{p}<0.001(t$-test $)$ \\
\hline $\mathrm{SS} \mathrm{t}=0$ vs. SS $\rightarrow \mathrm{SS}$ & $\mathrm{p}<0.001$ (N-par.) & NS & $\mathrm{p}<0.001(t$-test $)$ & $\mathrm{p}<0.001$ (N-par.) \\
\hline $\mathrm{SS} \mathrm{t}=0$ vs. SS $\rightarrow \mathrm{CE}$ & NS (N-par.) & NS & $\mathrm{p}<0.001(t$-test $)$ & $\mathrm{p}<0.01(t$-test $)$ \\
\hline
\end{tabular}

0.001), significantly affected the thickness of the distal section of the byssus secreted by the mussels. Distal thickness of the threads secreted by the outer exposed $\mathrm{CE} \rightarrow$ CE native animals was significantly higher than those secreted by the inner sheltered $\mathrm{SS} \rightarrow \mathrm{SS}$ natives. After 3 mo of transplant from inner sheltered SS to exposed CE conditions, threads secreted by the mussels showed an increase in the thickness up to similar native values $(\mathrm{CE} \rightarrow \mathrm{CE})$. The opposite native populations, i.e. $\mathrm{SS} \rightarrow \mathrm{CE}$ and $\mathrm{CE} \rightarrow \mathrm{SS}$ mussels significantly decreased and increased both GI and CI values, respectively (Fig. 5C,D).

\section{Tenacity}

Tenacity of mussels in the transplant experiment is presented in Fig. 6. Origin had no effect on mussel tenacity, but site did (ANOVA, p < 0.01). Tenacity of native $\mathrm{CE} \rightarrow \mathrm{CE}$ mussels was 2 -fold higher than that of $\mathrm{SS} \rightarrow$ SS native mussels; however, after 3 mo of transplant from outer exposed CE to inner sheltered SS conditions, mussels decreased significantly in tenacity down to values not significantly different than $\mathrm{SS} \rightarrow \mathrm{SS}$ natives. $\mathrm{SS} \rightarrow \mathrm{CE}$ mussels showed a significant increase in tenacity $(35 \%)$ up to values not significantly different than $\mathrm{CE} \rightarrow \mathrm{CE}$ native. It is important to note that mortality was not reported for all mussel populations, with the exception of the inner sheltered SS mussels transplanted to the outer exposed site CE $(\mathrm{SS} \rightarrow \mathrm{CE})$ in which $33 \%$ of the population was lost. Clearly mussels were too weak to make a secure byssus under the latter experimental condition.

Byssus size, mechanical properties and amino acid composition

Size of the byssus secreted by mussels in the transplant experiment is illustrated in Table 5. Variability of the proximal thickness of the byssus remained unaffected by site and origin, nor was the interaction term significant. Values varied within the range 120-135 $\mu \mathrm{m}$ for all mussel populations. However, both site $(p<0.05)$ and origin $(\mathrm{p}<0.001)$, as well as its interaction $(\mathrm{p}<$ surprisingly did not show any significant change compared with $\mathrm{CE} \rightarrow \mathrm{CE}$ natives, which established asymmetry for the plasticity of this morphological feature of the byssus structure. Length of byssus secreted by the mussels was significantly affected by site $(p<0.05)$ but not by the origin of individuals. Mussels located in the inner sheltered SS site (both native $\mathrm{SS} \rightarrow \mathrm{SS}$ and transplanted $\mathrm{CE} \rightarrow \mathrm{SS}$ ) secreted significantly longer byssal threads ( $p<0.05$ ) than mussels located in the outer exposed $\mathrm{CE}$ site (both native $\mathrm{CE} \rightarrow \mathrm{CE}$ and transplanted $\mathrm{SS} \rightarrow \mathrm{CE}$ ).

In general, mechanical properties of the byssus collected from the transplant experiment followed a pattern similar to that presented for distal thread thickness (Table 5). Byssus load values varied significantly with the origin of mussels $(p<0.05)$ and the interaction term Site $\times$ Origin $(p<0.01)$. Load values were significantly higher in the outer exposed native $\mathrm{CE} \rightarrow \mathrm{CE}$ mussels compared with the inner sheltered native $\mathrm{SS} \rightarrow \mathrm{SS}$ mussels. After 3 mo of transplant from sheltered SS to exposed CE conditions, threads secreted by the mussels showed an increase in load that can be sustained up to similar native values ( $\mathrm{CE} \rightarrow \mathrm{CE}$ ). Mussels $\mathrm{CE}$ to sheltered SS, continued to produce strong threads, similar in strength to those of the native $\mathrm{CE} \rightarrow \mathrm{CE}$ mussels (see asymmetry for the plasticity of this parameter in Table 5). Strain varied within the range of $0.56-0.73$ for all mussel populations but no significant effect of site or origin could be detected (ANOVA, p > 0.05). Similarly to load, yield values were significantly higher in the outer exposed native $\mathrm{CE} \rightarrow \mathrm{CE}$ mussels compared with the inner sheltered native $\mathrm{SS} \rightarrow \mathrm{SS}$ mussels. After 3 mo of transplantation, there was an increase in the yield values of the threads way of transplant (from exposed CE to sheltered SS) transplanted in the opposite direction, from exposed 

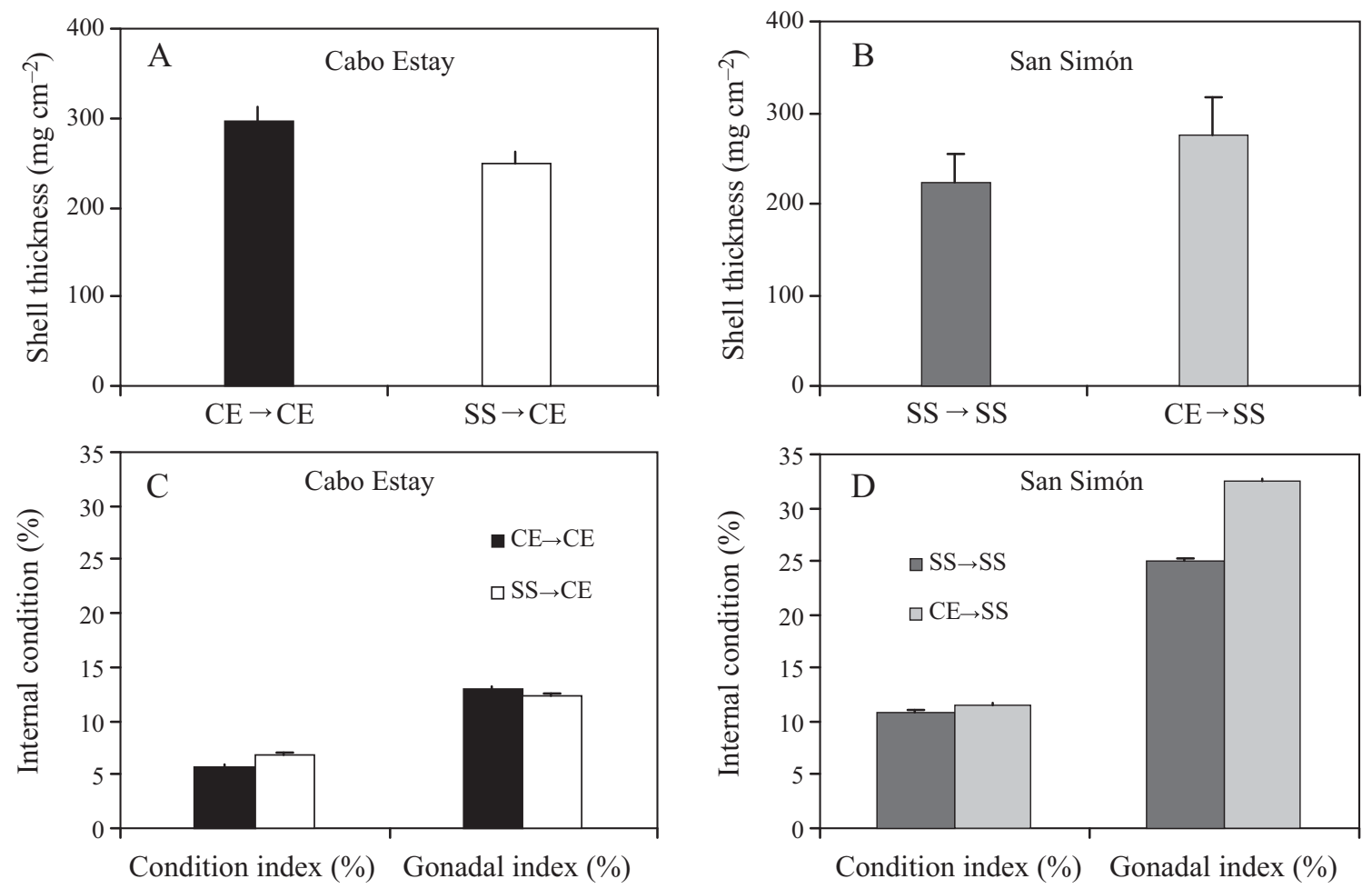

Fig. 5. Mytilus galloprovincialis. Transplant experiment. (A,B) Shell thickness and (C,D) gonadal and condition indices of experimental mussels after transplantation between exposed (Cabo Estay: CE) and sheltered (San Simón: SS) intertidal sites

secreted by the sheltered population transplanted to the exposed site ( $\mathrm{SS} \rightarrow \mathrm{CE}$ ) up to values similar to those of CE population, though the transplant in the opposite direction (from the exposed to the sheltered sites) did not cause any change with regard to the original exposed CE site. Modulus value of the byssus was significantly affected by site $(\mathrm{p}<0.05)$, with no influence of the origin of mussels in the transplant experiment, values being significantly higher for the threads secreted at the outer exposed CE site (by both natives and transplanted) compared with those secreted at the

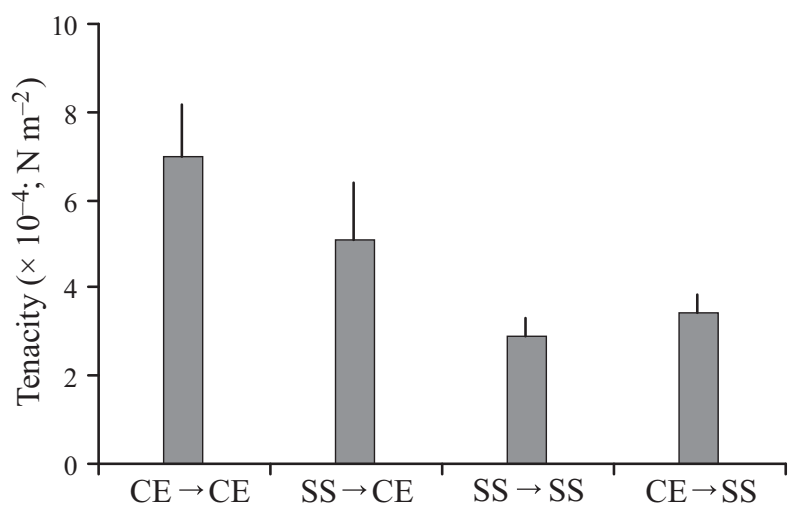

Fig. 6. Mytilus galloprovincialis. Transplant experiment. Tenacity values of the whole mussel after transplantation between exposed (Cabo Estay: CE) and sheltered (San Simón: SS) intertidal sites inner sheltered SS site. Scaled force values of the threads were significantly higher in the outer exposed native mussels $\mathrm{CE} \rightarrow \mathrm{CE}$ compared with the innersheltered native mussels $\mathrm{SS} \rightarrow \mathrm{SS}$. After 3 mo of transplant from sheltered SS to exposed CE conditions, threads secreted by the mussels showed an increase in scaled force up to values similar to those of native mussels $(\mathrm{CE} \rightarrow \mathrm{CE})$. As was the case for other mechanical properties, scaled force of the byssus secreted by mussels transplanted from outer exposed CE to inner sheltered SS remained higher, similar to those of $\mathrm{CE} \rightarrow \mathrm{CE}$ mussels, which is represented by the asymmetry pattern for this value.

Specific amino acid compositional analyses of the acid-hydrolysed distal and proximal regions of the threads secreted by the mussels in the transplant experiment are illustrated in the Fig. 7. Here, we can report no significant effect of site or origin of mussels on quantity of byssal collagen, according to specific amino acids hydroxyproline and hydroxylysine for native and transplanted mussels (ANOVA results not shown; Fig. 7A). Distal and proximal values of both hydroxyproline plus hydroxylysine residues were $11-12.7 \%$ and $10-11.5 \%$, respectively (Fig. 7A). The sum of histidine and lysine residues in the proximal byssus showed no differences by site but were significantly affected by the origin of mussels transplanted (ANOVA, data not shown). Histidine and lysine 
Table 5. Mytilus galloprovincialis. Changes in mussel tenacity, byssus morphometrics and mechanical properties for the crosstransplant experiment between the inner sheltered (SS) and the outer exposed (CE) sites. Means \pm SD ( $\mathrm{n}=35-45$ for thread thickness; $\mathrm{n}=9$ for thread length and mechanical properties). NS: not significant. ${ }^{\text {nsd }}$ : transplanted mussels do not significantly differ from natives

\begin{tabular}{|c|c|c|c|c|c|c|c|c|c|c|c|c|}
\hline Population & \multicolumn{4}{|c|}{ Proximal } & \multicolumn{4}{|c|}{ Distal } & \multicolumn{4}{|c|}{ Thread length (mm) } \\
\hline Native $\mathrm{SS} \rightarrow \mathrm{SS}$ & \multicolumn{4}{|c|}{$120.3 \pm 15.8$} & \multicolumn{4}{|c|}{$69.3 \pm 6.6$} & \multicolumn{4}{|c|}{$16.8 \pm 3.0$} \\
\hline Native $\mathrm{CE} \rightarrow \mathrm{CE}$ & \multicolumn{4}{|c|}{$123.9 \pm 25.2$} & \multicolumn{4}{|c|}{$87.7 \pm 10.0$} & \multicolumn{4}{|c|}{$14.1 \pm 1.7$} \\
\hline Transplanted SS $\rightarrow$ CE & \multicolumn{4}{|c|}{$134.8 \pm 23.7^{\mathrm{nsd}}$} & \multicolumn{4}{|c|}{$88.1 \pm 6.1^{\mathrm{nsd}}$} & \multicolumn{4}{|c|}{$14.7 \pm 3.1^{\mathrm{nsd}}$} \\
\hline \multicolumn{13}{|l|}{ Factor } \\
\hline Site & 1 & 0.00014 & 0.005 & NS & 1 & 0.023 & 6.4 & $<0.05$ & 1 & 0.327 & 4.233 & $<0.05$ \\
\hline Origin & 1 & 0.089 & 3.423 & NS & 1 & 0.259 & 72.1 & $<0.001$ & 1 & 0.003 & 0.042 & NS \\
\hline Site $\times$ Origin & 1 & 0.003 & 0.123 & NS & 1 & 0.300 & 83.4 & $<0.001$ & 1 & 0.008 & 0.103 & NS \\
\hline Error & 150 & \multicolumn{2}{|c|}{ Symmetry } & & 174 & \multicolumn{3}{|c|}{ Asymmetry } & 34 & \multicolumn{3}{|c|}{ Symmetry } \\
\hline
\end{tabular}

residues remained similar in the comparison between native outer exposed CE and inner sheltered SS mussels ( $\mathrm{p}>0.05)$, although values in the proximal sections of the threads were significantly higher $(3.1-4 \%)$ than those reported for the distal sections $(2.0-2.2 \%, \mathrm{p}<$ 0.01; Fig. 7B). Transplanted mussels showed a significant drop in histidine plus lysine residues of the proximal byssus, regardless of origin (Fig. 7B). No effect of site or origin (or its interaction term) was reported for the histidine and lysine residues in the distal section of the byssus (ANOVA results not shown; Fig. 7B).

\section{DISCUSSION}

The main aim of the present study was to investigate how a specific scenario within a single Ría can affect
Mytilus galloprovincialis performance with regard to attachment strength and associated parameters. The abiotic environment of the selected sites differed in the hydrodynamics and salinity gradients within the Ría de Vigo, and clearly modified the morphology of the individuals and their byssus secretion in situ. Individuals presented a more hydrodynamic shape to withstand rougher seas in the outer exposed site (CE) of Ría de Vigo and energy allocation patterns shifted to protective structures, such as shell thickness and byssus secretion. Indeed, hydrodynamic stress depends not only on water velocity but also on shell shape and the area over which the force acts (Denny 1995, Zardi et al. 2006); consequently, outer exposed mussels at CE would offer better resistance to dislodgment by modifying their shape, making lower and wider shells similar to the patterns reported by Bell \&
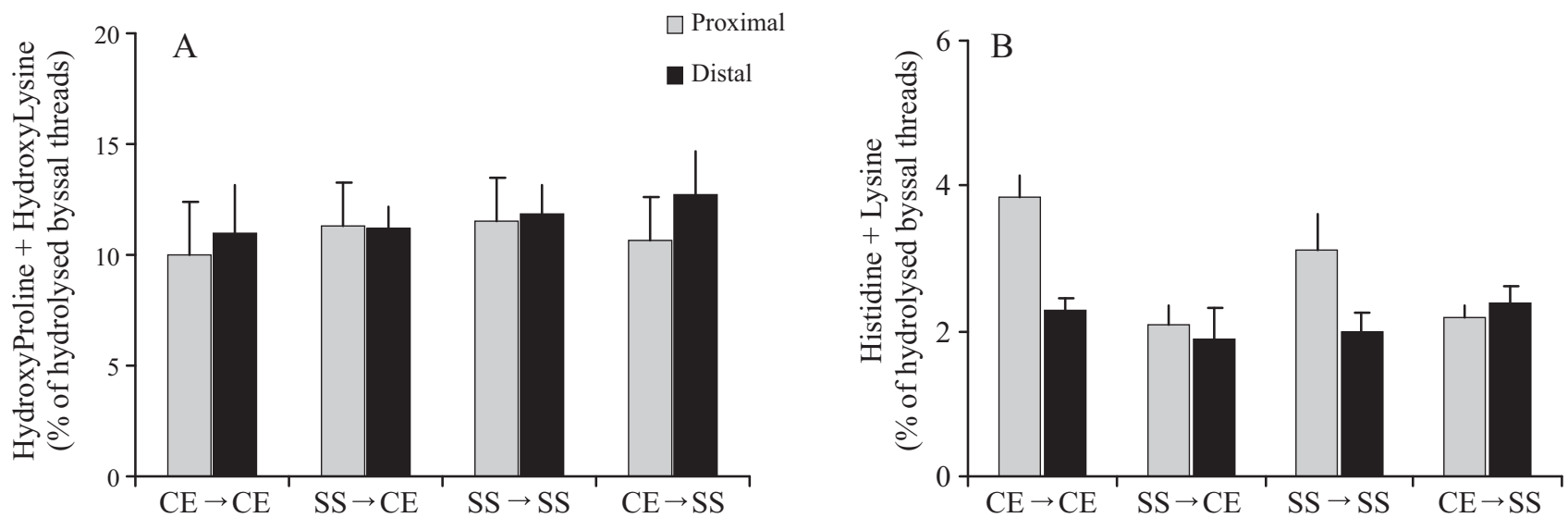

Fig. 7. Mytilus galloprovincialis. Transplant experiment. Hydroxyproline plus hydroxylysine (A) and histidine plus lysine (B) residues of the hydrolysed byssal thread portions (proximal and distal) secreted by experimental mussels after transplantation between outer exposed (Cabo Estay: CE) and inner sheltered (San Simón: SS) intertidal sites 
Table 5 (continued)

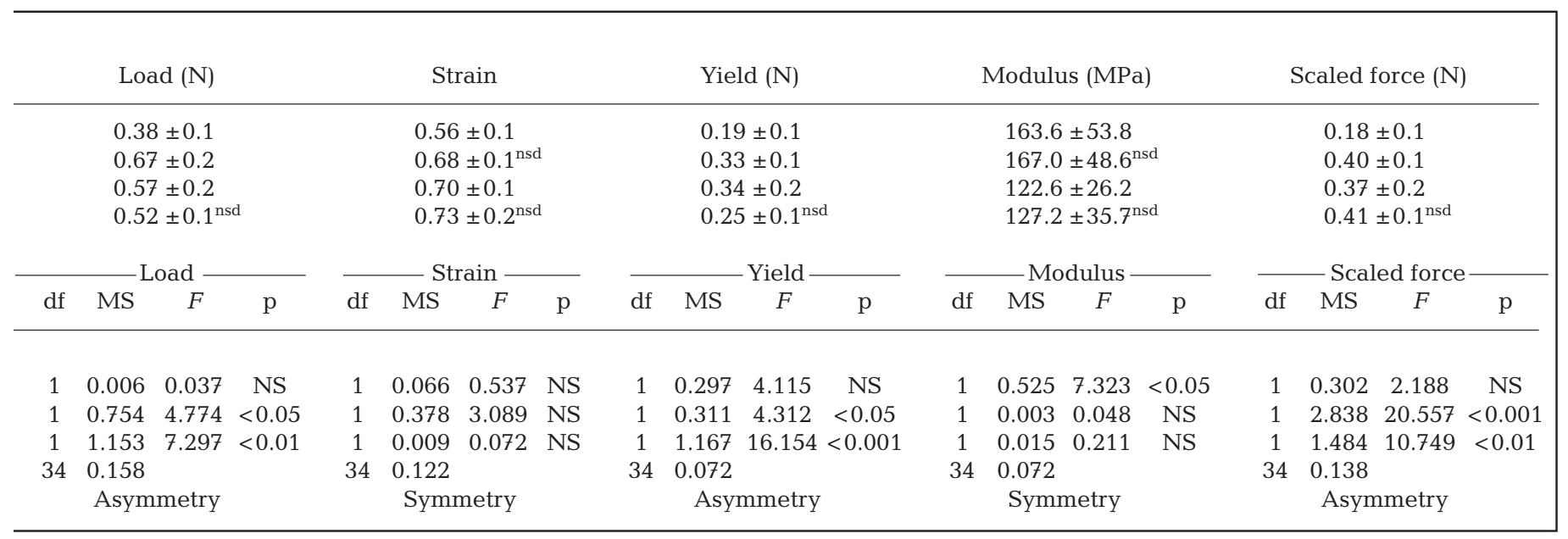

Gosline (1997). Steffani \& Branch (2003) have also shown that shells of $M$. galloprovincialis tended to be lower at more exposed sites in order to reduce the area over which hydrodynamic lift acts, preventing the risk of dislodgement.

The more energy allocated to protective structures (i.e. shell thickness, shell tissue and byssus), the lower the energy available for soft tissue growth, as can be seen in the lower CI and GI values for the outer exposed CE population, regardless of vertical zonation (location). Similar trade-off patterns between soft tissue growth and byssus secretion were reported by Raubenheimer \& Cook (1990), Carrington (2002) and Moeser \& Carrington (2006).

An increase in shell thickness is required to withstand the destructive and erosive effects of wave action. With our experimental design, however, we cannot entirely exclude predation as an important factor to explain shell thickness differences. However, because we observed similar distributions of the gastropod Nucella lapillus, one of the major predators on littoral mussel populations in this region (Barreiro et al. 1999), we assumed that differences encountered in our survey can be considered mainly driven by abiotic variability (Figs. 3,4). Shell thickness and mussel tenacity values were $20-26 \%$ higher in the mussels placed at the outer exposed CE site compared with the inner sheltered SS individuals in the outplant experiment, but surprisingly, no effect was observed for intertidal exposure (20-0\% emersion). The degree of emersion considered in the present study was based on the actual space mainly occupied by the mussels in the field, and emersion clearly did not affect animal behavior here. The absence of any significant effect of vertical zonation (location) in our survey was observed not only on the whole mussel tenacity but also on those parameters that eventually confer byssal strength, i.e. byssus morphology, mechanical properties and compositional values (Tables 1-3).

Although high-energy shores can be advantageous in terms of tidal exchange and higher food availability compared with more sheltered environments (Steffani \& Branch 2003), here, mussels inhabiting the more benign inner SS environment benefited from the fact that less energy had to be channelled into the byssus and shell thickness and mass formation. We found significantly higher CI and GI values in the inner sheltered SS mussel populations, which may be linked to both less energy channelled to byssus and shell thickening but also to higher seawater load (particulate matter) in this environment in both experiments (Figs. $3 \mathrm{~F} \& 4 \mathrm{E}, \mathrm{F})$. Although chl a values were occasionally higher at the highly exposed site CE, TPM was 3-fold higher at the inner sheltered SS, suggesting that many other fractions of particulate material or food resources are used by the individuals in the sheltered site of the Ría, such as mixture of suspended micro-phytobenthos and phytoplankton of marine origin. The benefit that bivalves can obtain from these seston fractions has been confirmed using stable isotope analysis for Crassostrea gigas (Riera \& Richard 1997) and Cerastoderma edule (Kang et al. 1999) in the Bahía de MarennesOléron and Macoma balthica, Scrobicularia plana and Mytilus edulis in la Bahía de Aiguillon (Riera et al. 1999).

Studies concerning the plasticity or ability of mussels to alter compositional or mechanical properties of the byssus secretion under changing environments are not abundant. We have reported here the importance of the macro-geographical factor of site on a number of 
parameters associated with byssus secretion: byssus morphology, compositional values and mechanical properties. Differences in wave activity (flow regime, wave height and/or turbulence) between our experimental sites must be clearly related to the differences reported for the byssus secretion, as was suggested by Hunt \& Scheibling (2001) and Lachance et al. (2008). The higher tenacity reported for the outer exposed CE mussels was not only due to the thicker byssal threads these animals secreted, specifically at its distal sections, but was also a consequence of the fact that these threads were mechanically more effective (Table 3) and had a higher amount of the basic amino acids histidine and lysine (Table 1).

The importance of histidine and lysine in the byssal collagen of the mussel Mytilus galloprovincialis has been identified in animals subjected to endogenous stress such as spawning events. Babarro \& Fernández Reiriz (2010) reported the ability of mussels to carry out compositional changes for increasing attachment force when needed and established variations in the amino acid composition of the distal section of the byssus. Here, we extended this information to the proximal sections of the byssus secreted by the experimental mussels (Table 1). Residues of both lysine and histidine produce cross-links, joining 2 or more molecules; histidine in particular has a pronounced effect on metal chelation and/or cross-link ability (Waite et al. 1998) as well as the capacity to form a significant part (up to $22 \mathrm{~mol} \%$ in protein mcfp-4) of the junction between collagen fibres and foam-like adhesive plaques in the mussel Mytilus californianus (Zhao \& Waite 2006). Whenever histidine-rich domains occur in proteins, they usually bind with metal; the byssal collagen of $M$. galloprovincialis has been reported to contain additional histidine residues in its flanking domains, which can help to utilise more metal chelate cross-link for byssal stability and integrity (Lucas et al. 2002). Plasticity patterns in the mussel byssus were also reported by McDowell et al. (1999), with an increased formation of quinone-derived cross-links in mussel byssal plaques when individuals were exposed to higher flow regimes, which might lead to establish better attachment of the individuals to the substratum. It is also important to note that when threads yield, the stress softening is reversible in a time-dependent manner (Carrington \& Gosline 2004), and that histidine-metal interactions are reported as the perfect candidate for a sacrificial cross-link because they can break and reform reversibly and are weaker than covalent bonds (Schmitt et al. 2000).

The distal section of the byssus has been established as a main factor involved in the variability in tenacity of mussels (Bell \& Gosline 1997, Brazee \& Carrington 2006, Babarro \& Fernández Reiriz 2010). Similar pat- terns were observed here, in contrast to a rather constant value for the proximal section diameter (Table 2). Nevertheless, mechanical properties of the byssus followed, in the present survey, patterns similar to those of distal byssus diameter (see Tables $2 \& 3$ ) and are primarily responsible for the differences in mussel tenacity. Thickness of the proximal sections of the byssus were narrower $(159-170 \mu \mathrm{m})$ in all mussel populations during the first outplant survey, but the fact that compositional values, i.e. the amount of histidine and lysine residues, were also significantly higher in the most exposed CE mussels (38\%) regardless of byssal section (proximal and distal) suggests that both thread diameter and amino acid composition significantly influence mussel tenacity.

Mussels transplanted between intertidal sites showed values similar to native individuals for a number of parameters, such as tenacity, endogenous (gonadal and condition) indices, byssus morphology (length and thickness) and mechanical properties, although this pattern depended on the transplantation direction. A complete shift was observed in mussels transplanted to the most exposed CE environment, suggesting that the increase in the byssus strength was necessary to cope with a rougher habitat. This was accomplished through an increase in byssus diameter (distal) and a number of mechanical properties (Table 5). The opposite direction of transplant (from the outer exposed CE to the inner sheltered SS) resulted in a shift in tenacity, GI and CI, and thread length (Table 5, Figs. 5C,D \& 6), but neither thread diameter nor mechanical properties showed any significant change (Table 5). Surprisingly, mussels transplanted to the inner sheltered SS site continued to secrete thick (and strong) byssus despite the relatively benign environment, and established a clear asymmetry for parameters such as distal thread thickness, maximum load, yield and scaled force (Table 5). Most likely, in the latter case, change in tenacity of the whole mussel may have been achieved by a drop in the number of byssal threads secreted, thereby saving energy for other purposes, i.e. soft tissue growth (Fig. 5C,D). In other words, the secretion of thick and strong byssus by those mussels originally from the outer exposed CE site and transplanted to the inner sheltered SS site ( $\mathrm{CE} \rightarrow \mathrm{SS}$ ) must be energetically not that costly, at least when compared with the secretion of more new threads, and especially when such an environmental change offers the mussels better food resources (Fig. 4E,F). Here, we may consider the significant influence of the past history or ecological memory (Suhkotin \& Pörtner 1999), according to which animals have a record of the past events in the their natural environments, which may introduce a temporal dependence in their new responses when facing abrupt environmental changes. Accordingly, such influence of 
past history for the animals living at the most exposed site would be significant when mussels were transplanted to more benign waters and they would need longer to completely adapt to this new sheltered habitat. For the opposite transplant direction, from the inner sheltered to the outer exposed site, mussels would be undoubtedly forced to secrete thicker and stronger byssus threads much more quickly for a better attachment in a stressful environment with regard to the original more benign habitat.

Surprisingly, modulus values showed the opposite pattern between outplant and transplant experiments in the site comparison (Tables $3 \& 5$ ) and were the only mechanical property that presented complete symmetry regardless of the direction of the transplant (Table 5). Modulus values were higher in the outer exposed CE mussels in fall 2007 (Table 3) but this pattern was reversed in spring-summer 2008 (Table 5). The mechanism for the observed differences in modulus is not clear, but might be dependent on numerous environmental and physiological factors (Moeser \& Carrington 2006). Modulus has been related to the degree of cross-linking or crystallinity in a material (Vaccaro \& Waite 2001), which in turn establishes the degree of structural order in a fiber. The presence of metals, i.e. iron and manganese, are necessary for the cross-link of byssal thread proteins (Waite et al. 2002) and changes in the water chemistry might also result in variability in molecular interactions in a byssal thread and, consequently, in their mechanical behaviour (Sun et al. 2001). Investigation of how this may affect byssal thread quality is an interesting possibility for future research. The seasonal distribution of metals in Rías Gallegas and, specifically in Ría de Vigo, has been associated with the input of rivers, more significant in fall-winter periods, and the specific concentration of metals such as $\mathrm{Al}, \mathrm{Fe}$ and $\mathrm{Mn}$ appeared to be associated with these freshwater flows into the Rías (Villares et al. 2002). This abiotic impact, together with the endogenous variability of mussels seasonally, might help to explain differences encountered for this thread mechanical value (modulus) between outplant and transplant experiments carried out in 2 different seasons.

Overall, this study reports a highly dynamic value for byssus secretion in mussels as well as plasticity patterns in the attachment strength associated with abrupt changes in the environment. Mussels have the ability to modify byssus size and mechanical properties to ensure attachment strength, but this response depends on the degree of environmental change. Mussles can re-allocate more energy to other vital processes, such as gonadal and soft tissue growth in more benign environments, shifting energy from the production of a protective byssus and shell.
Acknowledgements. We thank E. Silva Caride for technical assistance in the field and laboratory and C. Craig for mechanical analysis of the byssus. J.M.F.B. also thanks support and help provided by J. L. Garrido. This study was partly funded by NSF grant EF1041213 to E.C. J.M.F.B. acknowledges the funding of the projects AGL2006-06986/ACU and AGL2010-16464 (Ministerio de Ciencia e Innovación, Spanish Government).

\section{LITERATURE CITED}

Akester RJ, Martel AL (2000) Shell shape, dysodont tooth morphology and hinge-ligament thickness in the bay mussel Mytilus trossulus correlate with wave exposure. Can J Zool 78:240-253

Babarro JMF, Fernández Reiriz MJ (2010) Secretion of byssal threads in Mytilus galloprovincialis: quantitative and qualitative values after spawning stress. J Comp Physiol B 180:95-104

Babarro JMF, Fernández-Reiriz MJ, Labarta U (2008) Secretion of byssal threads and attachment strength of Mytilus galloprovincialis: the influence of size and food availability. J Mar Biol Assoc UK 88:783-791

Barreiro R, Quintela M, Ruiz JM (1999) Aphally and imposex in Nucella lapillus from Galicia (NW Spain): incidence, geographical distribution and consequences for the biomonitoring of TBT contamination. Mar Ecol Prog Ser 185: $229-238$

Beadman HA, Caldow RWG, Kaiser MJ, Willows RI (2003) How to toughen up your mussels: using shell morphological plasticity to reduce predation losses. Mar Biol 142: 487-494

Bell EC, Gosline JM (1996) Mechanical design of mussel byssus: material yield enhances attachment strength. J Exp Biol 199:1005-1017

Bell EC, Gosline JM (1997) Strategies for life in flow: tenacity, morphometry, and probability of dislodgment of two Mytilus species. Mar Ecol Prog Ser 159:197-208

Brazee SL, Carrington E (2006) Interspecific comparison of the mechanical properties of mussel byssus. Biol Bull 211: 263-274

Brown CH (1952) Some structural proteins of Mytilus edulis L. Q J Microsc Sci 93:487-502

> Carrington E (2002) Seasonal variation in the attachment strength of blue mussels: causes and consequences. Limnol Oceanogr 47:1723-1733

Carrington E, Gosline JM (2004) Mechanical design of mussel byssus: load cycle and strain rate dependence. Am Malacol Bull 18:135-142

Coyne KJ, Qin XX, Waite JH (1997) Extensible collagen in mussel byssus: a natural block copolymer. Science 277 : 1830-1832

Denny MW (1995) Predicting physical disturbance: mechanistic approaches to the study of survivorship on wave-swept shores. Ecol Monogr 65:371-418

Freeman KR (1974) Growth, mortality and seasonal cycle of Mytilus edulis in two Nova Scotian embayments. Tech Rep No. 500, Department of the Environment, Fisheries and Marine Service, Dartmouth, Canada

> Gardner JPA, Thomas MLH (1987) Growth, mortality and production of organic matter by a rocky intertidal population of Mytilus edulis in the Quoddy Region of the Bay of Fundy. Mar Ecol Prog Ser 39:31-36

> Harrington MJ, Waite JH (2007) Holdfast heroics: comparing the molecular and mechanical properties of Mytilus californianus byssal threads. J Exp Biol 210:4307-4318 
Hawkins AJS, Bayne BL (1985) Seasonal variation in the relative utilization of carbon and nitrogen by the mussel Mytilus edulis: budgets, conversion efficiencies and maintenance requirements. Mar Ecol Prog Ser 25:181-188

$>$ Hunt HL, Scheibling RE (2001) Predicting wave dislodgment of mussels: variation in attachment strength with body size, habitat, and season. Mar Ecol Prog Ser 213:157-164

Kang CK, Sauria PG, Richard P, Blanchard GF (1999) Food sources of the infaunal suspension-feeding bivalve Cerastoderma edule in a muddy sandflat of Marennes-Oléron Bay, as determined by analyses of carbon and nitrogen stable isotopes. Mar Ecol Prog Ser 187:147-158

Krause I, Bockhardt A, Neckermann H, Henle T, Klostermeyer H (1995) Simultaneous determination of amino acids and biogenic amines by reverse-phase high-performance liquid chromatography of the dabsyl derivatives. J Chromatogr A 715:67-79

> Lachance AA, Myrand B, Tremblay R, Koutitonsky V, Carrington $\mathrm{E}$ (2008) Biotic and abiotic factors influencing attachment strength of blue mussels Mytilus edulis in suspended culture. Aquat Biol 2:119-129

Lucas JM, Vaccaro E, Waite JH (2002) A molecular, morphometric and mechanical comparison of the structural elements of byssus from Mytilus edulis and Mytilus galloprovincialis. J Exp Biol 205:1807-1817

McDowell LM, Burzio LA, Waite JH, Schaefer J (1999) Rotational echo double resonance detection of cross-links formed in mussel byssus under high-flow stress. J Biol Chem 274:20293-20295

Moeser GM, Carrington E (2006) Seasonal variation in mussel thread mechanics. J Exp Biol 209:1996-2003

Moeser GM, Leba H, Carrington E (2006) Seasonal influence of wave action on thread production in Mytilus edulis. J Exp Biol 209:881-890

Pinho O, Ferreira IMPLVO, Mendes E, Oliveira BM, Ferreira M (2001) Effect of temperature on evolution of free amino acid and biogenic amine contents during storage of Azeitão cheese. Food Chem 75:287-291

Pujol JP, Rolland M, Lasry S, Vinet S (1970) Comparative study of the amino acid composition of the byssus in some common bivalve molluscs. Comp Biochem Physiol 34:193-201

Pujol JP, Bocquet J, Borel JP (1976) Le byssus de Mytilus: etude electrophoretique de fractions proteiques riches en hydroxyproline extraites de la 'glande du collagene'. C R Seances Acad Sci Paris 283 D:555-558

Qin XX, Waite JH (1998) A potential mediator of collagenous block copolymer gradients in mussel byssal threads. Proc Natl Acad Sci USA 95:10517-10522

Raubenheimer D, Cook P (1990) Effects of exposure to wave action on allocation of resources to shell and meat growth by the subtidal mussel, Mytilus galloprovincialis. J Shellfish Res 9:87-93

Riera P, Richard P (1997) Temporal variation of $\delta^{13} \mathrm{C}$ in particulate organic matter and oyster Crassostrea gigas in

Editorial responsibility: Matthias Seaman, Oldendorf/Luhe, Germany
Marennes-Oléron Bay (France): effect of freshwater inflow. Mar Ecol Prog Ser 147:105-115

Riera P, Stal LJ, Nieuwenhuize J, Richard P, Blanchard G, Gentil F (1999) Determination of food sources for benthic invertebrates in a salt marsh (Aiguillon Bay, France) by carbon and nitrogen stable isotopes: importance of locally produced sources. Mar Ecol Prog Ser 187:301-307

Schmitt L, Ludwig M, Gaub HE, Tampe R (2000) A metalchelating microscopy tip as a new toolbox for a singlemolecule experiments by atomic force microscopy. Biophys J 78:3275-3285

Smeathers JE, Vincent JFV (1979) Mechanical properties of mussel byssus threads. J Molluscan Stud 45:219-230

Steffani CN, Branch GM (2003) Growth rate, condition, and shell shape of Mytilus galloprovincialis: responses to wave exposure. Mar Ecol Prog Ser 246:197-209

Sukhotin AA, Pörtner HO (1999) Habitat as a factor involved in the physiological response to environmental anaerobiosis of White Sea Mytilus edulis. Mar Ecol Prog Ser 184: $149-160$

Sun C, Waite JH (2005) Mapping chemical gradients within and along fibrous structural tissue, mussel byssal threads. J Biol Chem 280:39332-39336

Sun C, Vaccaro E, Waite JH (2001) Oxidative stress and the mechanical properties of naturally occurring chimeric collagen-containing fibers. Biophys J 81:3590-3595

> Vaccaro E, Waite JH (2001) Yield and post-yield behaviour of mussel byssal thread: a self-healing biomolecular material. Biomacromolecules 2:906-911

Villares R, Puente X, Carballeira A (2002) Seasonal variation and background levels of heavy metals in two green seaweeds. Environ Pollut 119:79-90

Waite JH (1992) The formation of mussel byssus: anatomy of a natural manufacturing process. In: Case ST (ed) Results and problems in cell differentiation, Vol 19, Biopolymers. Springer, Berlin, p 27-54

Waite JH, Qin XX, Coyne KJ (1998) The peculiar collagens of mussel byssus. Matrix Biol 17:93-106

Waite JH, Vaccaro E, Sun C, Lucas JM (2002) Elastomeric gradients: a hedge against stress concentration in marine holdfasts? Philos Trans R Soc Lond B 357:143-153

Zardi GI, Nicastro KR, McQuaid CD, Rius M, Porri F (2006) Hydrodynamic stress and habitat partitioning between indigenous (Perna perna) and invasive (Mytilus galloprovincialis) mussels: constraints of an evolutionary strategy. Mar Biol 150:79-88

Zardi GI, McQuaid CD, Nicastro KR (2007) Balancing survival and reproduction: seasonality of wave action, attachment strength and reproductive output in indigenous Perna perna and invasive Mytilus galloprovincialis mussels. Mar Ecol Prog Ser 334:155-163

> Zhao H, Waite JH (2006) Proteins in load-bearing junctions: the histidine-rich metal-binding protein of mussel byssus. Biochemistry 45:14223-14231

Submitted: January 20, 2011; Accepted: May 5, 2011 Proofs received from author(s): July 27, 2011 